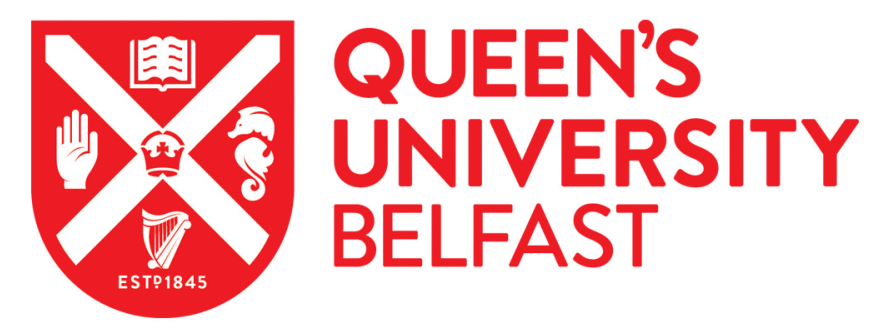

\title{
Type 3 Porous Liquids for the Separation of Ethane and Ethene
}

Lai, B., Cahir, J., Tsang, M. Y., Jacquemin, J., Rooney, D., Murrer, B., \& James, S. (2020). Type 3 Porous Liquids for the Separation of Ethane and Ethene. ACS Applied Materials and Interfaces. https://doi.org/10.1021/acsami.0c19044

\section{Published in:}

ACS Applied Materials and Interfaces

\section{Document Version:}

Peer reviewed version

\section{Queen's University Belfast - Research Portal:}

Link to publication record in Queen's University Belfast Research Portal

\section{Publisher rights}

Copyright 2020 American Chemical Society. This work is made available online in accordance with the publisher's policies. Please refer to any applicable terms of use of the publisher.

\section{General rights}

Copyright for the publications made accessible via the Queen's University Belfast Research Portal is retained by the author(s) and / or other copyright owners and it is a condition of accessing these publications that users recognise and abide by the legal requirements associated with these rights.

Take down policy

The Research Portal is Queen's institutional repository that provides access to Queen's research output. Every effort has been made to ensure that content in the Research Portal does not infringe any person's rights, or applicable UK laws. If you discover content in the Research Portal that you believe breaches copyright or violates any law, please contact openaccess@qub.ac.uk. 


\title{
Type 3 Porous Liquids for the Separation of Ethane and Ethene
}

\author{
Beibei Lai, ${ }^{\dagger}$ John Cahir, ${ }^{\dagger}$ Min Ying Tsang,${ }^{\dagger}$ Johan Jacquemin, ${ }^{\ddagger}$ David Rooney, ${ }^{\dagger}$ Barry Murrer, ${ }^{\dagger}$ and Stu- \\ art L. James*† \\ † School of Chemistry and Chemical Engineering, Queen's University Belfast, David Keir Building, Stranmillis Road, Bel- \\ fast, BT9 5AG, UK. \\ ‡Laboratoire PCM2E, Universit ’e de Tours, Parc de Grandmont, 37200 Tours, France. \\ KEYWORDS: Porous liquids, ethane/ethene separation, metal organic frameworks, zeolites, ionic liquids.
}

\begin{abstract}
We assess the potential for formulating a porous liquid that could be used as a selective solvent for the separation of ethane and ethene. Ethane-ethene separation is performed on very large scales by cryogenic distillation, but this uses large amounts of energy. Solvents that are selective to ethane or ethene could potentially enable more efficient liquid-based separation processes to be developed, but such solvents have been elusive to date. Here, Type 3 porous liquids, which consist of microporous solids dispersed in size-excluded liquid phases, have been tailored toward the separation of ethane and ethene. High selectivity for ethene over ethane (25.6 at 0.8 bar) and high capacity was achieved for zeolite AgA dispersed in an Ag-containing ionic liquid. Unusually for liquid phases, selectivity for ethane over ethene ( 2.55 at 0.8 bar) could also be achieved using the MOF $\mathrm{Cu}(\mathrm{Qc})_{2}(\mathrm{Qc}=$ quinoline-5-carboxylate) dispersed in sesame oil, or ZIF-7 in sesame oil, the latter showing gated uptake. The efficiency of the $\mathrm{Cu}(\mathrm{Qc})_{2}$ synthesis was increased by developing a mechanochemical method. Regeneration of $\mathrm{Cu}(\mathrm{Qc})_{2}$ in sesame oil and ZIF-7 in sesame oil was also demonstrated suggesting that these or similar porous liquids could potentially be applied in cyclic separation processes.
\end{abstract}

\section{Introduction}

Porous liquids (PLs) are materials that combine permanent porosity with fluidity. ${ }^{1}$ This blend of properties is unusual and potentially useful. In particular, the porosity of PLs can enable size-selective and/or shape-selective dissolution of solutes, whilst their fluidity enables them to be engineered into continuous cyclic separation processes. Three types of PLs have been proposed. ${ }^{1}$ Type 1 are neat molecular hosts in liquid form, Type 2 consist of molecular-scale hosts dissolved in solvents that are sizeexcluded from the host's cavity, and Type 3 consist of particles of microporous solids dispersed in liquids that are size excluded from the pores (Figure 1)..$^{2-6}$ Type 3 PLs are currently the most economical to prepare. They are also compositionally diverse and some of their critical properties (such as gas uptake) are predictable, making them designable. Overall, they constitute a broad platform of selective liquid sorbents that may be tailored toward applications..$^{7-14}$

The separation of ethane and ethene is one of the major industrial partitions. ${ }^{15}$ However, it is challenging due to the similar sizes and physical properties of these molecules. It is mostly achieved by cryogenic distillation, but this requires large amounts of energy, ${ }^{15}$ making the search for alternative methods important. Membrane technology is a potential alternative, ${ }^{16,17}$ but it can suffer from poisoning, low selectivity and mechanical failure. Liquid solvents that are selective for one gas over the other could enable continuous cyclic processes to be developed as alternatives to the above approaches. These would be analogous to existing liquid-based processes for natural gas sweetening (i.e. the separation of $\mathrm{CO}_{2}$ and $\mathrm{H}_{2} \mathrm{~S}$ from
$\mathrm{CH}_{4}$ ) currently performed with aqueous amines or oligoethylene glycol solvents. In this regard, etheneselective solvents containing metal cations, often silver(I), dissolved in water or in ionic liquids have been investigated. ${ }^{18}$ Also, we have previously described preliminary work with a porous liquid based on zeolite $\mathrm{AgA}^{19}$ dispersed in paraffin oil, which is ethene selective. ${ }^{7}$ However, the potential of PLs for ethane-ethene separation has not been explored in any detail. Considering the benefits an appropriate PL could bring, it is important to assess their potential for this application more broadly.

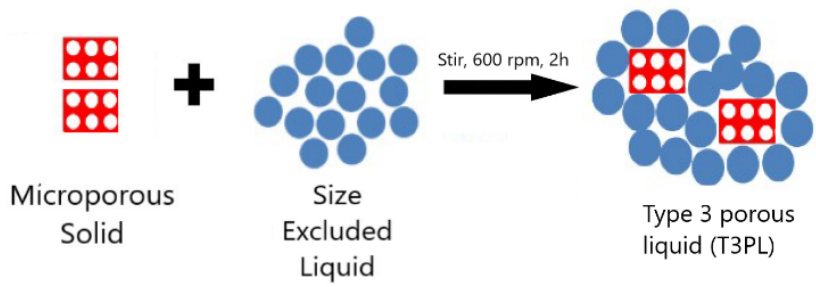

Figure 1. Schematic of the formation of a Type 3 porous liquid.

Here we describe various approaches to this challenge. Five PLs have been formulated and evaluated. We include an $\mathrm{Ag}(\mathrm{I})$-based porous liquid with very high ethene selectivity and capacity, and two PLs that, unusually for liquid solvents, exhibit significant ethane selectivity. These latter porous liquids can be readily regenerated making them amenable to continuous cyclic separations. 
Table 1. Ethane/ethene solubility in porous solids and pure liquid components investigated for Type 3 porous liquids.

\begin{tabular}{|c|c|c|c|c|c|}
\hline \multirow{2}{*}{ Materials } & \multicolumn{2}{|c|}{$\begin{array}{c}\text { Ethane uptake at } \\
0.8 \text { bar }(\mathrm{mmol} / \mathrm{g})\end{array}$} & \multicolumn{2}{c|}{$\begin{array}{c}\text { Ethene uptake at } \\
0.8 \text { bar }(\mathrm{mmol} / \mathrm{g})\end{array}$} & $\begin{array}{c}\text { Ethene Selectivity } \\
\text { at } 0.8 \text { bar }\end{array}$ \\
\cline { 2 - 6 } & Theo. & Exp. & Theo. & Exp. & 1.45 \\
\hline HKUST-1 & $4.79^{20}$ & 4.19 & - & 6.1 & 15.48 \\
\hline Zeolite AgA & $0.08^{19}$ & 0.125 & $2.12^{19}$ & 1.935 & $2.02^{*}$ \\
\hline Cu(Qc) 2 & $1.85^{21}$ & 1.662 & $0.78^{21}$ & 0.821 & $1.35^{*}$ \\
\hline Sesame oil & - & 0.096 & - & 0.071 & 33.13 \\
\hline AgIL & - & 0.015 & - & 0.497 & \\
\hline
\end{tabular}

Table 2. Type 3 porous liquids investigated for their ability to selectively adsorb ethane and ethene.

\begin{tabular}{|c|c|c|c|c|c|c|c|c|c|}
\hline \multirow{2}{*}{$\begin{array}{l}\text { Porous } \\
\text { liquid }\end{array}$} & \multirow{2}{*}{$\begin{array}{l}\text { Porous solid } \\
\text { component } \\
\text { (wt.\%) }\end{array}$} & \multirow{2}{*}{$\begin{array}{c}\text { Liquid } \\
\text { component }\end{array}$} & \multicolumn{3}{|c|}{$\begin{array}{l}\text { Ethane uptake at } \\
0.8 \mathrm{bar}(\mathrm{mmol} / \mathrm{g})\end{array}$} & \multicolumn{3}{|c|}{$\begin{array}{l}\text { Ethene uptake at } \\
0.8 \mathrm{bar}(\mathrm{mmol} / \mathrm{g})\end{array}$} & \multirow{2}{*}{$\begin{array}{c}\text { Ethene Selectivity } \\
\text { at } 0.8 \text { bar }\end{array}$} \\
\hline & & & Cal. & Exp. & $\sigma$ & Cal. & Exp. & $\sigma$ & \\
\hline 1 & $\begin{array}{c}\text { HKUST-1 } \\
(12.5)\end{array}$ & Sesame oil & 0.61 & 0.67 & 0.01 & 0.83 & 0.84 & 0.01 & 1.25 \\
\hline 2 & $\begin{array}{c}\text { Zeolite AgA } \\
\quad(12.5)\end{array}$ & AgIL & 0.02 & 0.02 & 0.00 & 0.67 & 0.61 & 0.01 & 25.6 \\
\hline 3 & $\begin{array}{c}\text { Zeolite AgA } \\
\quad(25.0)\end{array}$ & AgIL & 0.04 & $\dagger 0.04$ & - & 0.86 & $\dagger 0.84$ & - & 21.0 \\
\hline 4 & $\begin{array}{c}\mathrm{Cu}(\mathrm{Qc})_{2} \\
(12.5)\end{array}$ & Sesame oil & 0.29 & 0.28 & 0.00 & 0.16 & $\ddagger 0.11$ & 0.00 & $2.55^{*}$ \\
\hline 5 & $\begin{array}{l}\text { ZIF-7 } \\
(12.5)\end{array}$ & Sesame oil & - & $0.016^{* *}$ & - & - & $0.12 * *$ & - & $7.5^{* *}$ \\
\hline
\end{tabular}

Key: Theo. is the literature gas uptakes, Cal. is the calculated or predicted uptake, i.e. the weighted averages of the uptakes of the individual liquid and solid components, Exp. is the experimental uptake and $\sigma$ is the standard deviation. AgIL = 1butyl-3-methylimidazolium bis(trifluoromethylsulfonyl)imide saturated with silver trifluoromethanesulfonate. * indicates ethane selectivity, $\dagger$ indicates measurements completed once and $\ddagger$ indicates values outside $10 \%$ of the predicted value. ** indicates the ethane/ethene uptakes and ethane selectivity of PL-5 were measured and calculated barometrically at 0.1 bar.

\section{Results and discussion}

In a previous general study, the gas uptakes of Type 3 porous liquids with typical solid loading of $12.5 \mathrm{wt} \%$ were found to be dominated by the solid component. ${ }^{7}$ Therefore, we began by selecting solid components that, from literature, have high uptakes or selectivities for ethane or ethene. The solid and liquid components of the five compositions investigated, PL-1-5, are summarised in Table 1, and the composition themselves are summarized in Table 2. Each consisted of 12.5 wt.\% of solid dispersed in the liquid phase, unless otherwise stated, and were prepared by vigorously stirring $(600 \mathrm{rpm})$ the solid in the liquid phase for 2 hours to give homogeneous dispersions that were found to be stable to sedimentation for at least 2 days.

Regarding the solids investigated, open metal sites can be effective for preferentially binding ethene through $\pi$ coordination, as in HKUST-1 (a MOF with open $\mathrm{Cu}$ (II) sites) ${ }^{22}$ or zeolite $\mathrm{AgA}$ (zeolite A containing $\mathrm{Ag}(\mathrm{I})$ cations). Conversely, selectivity for ethane over ethene in microporous solids is rare and there are no simple design strategies to achieve this. However, significantly, certain
MOFs such as $\mathrm{Cu}(\mathrm{Qc})_{2}(\mathrm{Qc}=$ quinoline-5-carboxylate $)$ and ZIF-7 have recently been shown to exhibit ethane selectivity, which has been ascribed to the greater polarizability of ethane over ethene ${ }^{21}$ or the pore window shape ${ }^{23}$.

Regarding the liquid components investigated, sesame oil (a triglyceride) and the Ag-containing ionic liquid (IL) 1butyl-3-methylimidazolium bis(trifluoromethylsulfonyl) imide saturated with silver trifluoromethanesulfonate $(0.18$ $\mathrm{g} / \mathrm{mL}$ ), here denoted AgIL, were chosen..$^{18,24}$ Critically, both these liquids should be sterically excluded from the pores of the solids due their branched structures, so that the pores remain empty and available to gases. Sesame oil has the advantage of being inexpensive and innocuous. Normal solvents are typically unselective for either ethane or ethene, with organic solvents commonly having modest selectivity for ethane over ethene. For example, sesame oil shows ethane selectivity of 1.35 (0.8 bar) (SI 7, Table $\mathrm{S} 5 / \mathrm{S} 7)$. In contrast, Ag-based ionic liquids show considerable selectivity for ethene (e.g., 33.13 for AgIL at 0.8 bar). The gas uptakes were screened initially using an isochoric method (at 0.8 bar) to confirm that the pores of the solids were indeed available to gases, before investigating higher 
pressures (1-5 bar) using a barometric method. ${ }^{7}$ All measurements equilibrated within two hours and were reproducible. Pure gases were used and selectivities were calculated using the ratio of the molar uptakes. Thus this data provide indicative values for selectivity despite the potential for differences between pure gases and binary mixtures as well as non-ideality. As hoped, and in line with previous work on porous liquids with $\mathrm{N}_{2}, \mathrm{CH}_{4}$ and $\mathrm{CO}_{2},{ }^{7}$ the experimental ethane and ethene uptakes of the porous liquids were within $10 \%$ of the weighted averages of the uptakes of their individual solid and liquid components unless otherwise stated. Uptake of gases in the porous solids were also similar to previously reported values (Table 1 ).

Due to the large pore volume $\left(0.71 \mathrm{~cm}^{3} / \mathrm{g}\right)$ of HKUST-1, PL-1 was able to adsorb large amounts of both ethene and ethane (0.84 and $0.67 \mathrm{mmol} / \mathrm{g}$ respectively) (Table 2). As expected, due to the presence of free $\mathrm{Cu}$ (II) sites, ${ }^{22}$ it was selective to ethene. However, the selectivity of the porous liquid (1.25) was modest overall since the liquid component, sesame oil, is slightly selective to ethane ( 1.35 for sesame oil) (SI 7, Table S5). Greater selectivity might be expected if mixed gases were used, as observed for the solid HKUST- $1 . .^{25}$

To improve selectivity for ethene, we combined $\mathrm{AgA}$ as the most ethene-selective solid ${ }^{19}$ with $\mathrm{AgIL}$ as the most ethene selective liquid (to give PL-2 and PL-3). Ionic liquids have been reported as size- excluded liquid components for Type 3 porous liquids ${ }^{7-14}$ and can also dissolve $\operatorname{Ag}(\mathrm{I})$ salts to make them ethene-selective. ${ }^{18}$

Zeolite $\mathrm{AgA}$ was dispersed in the bulky ionic liquid 1butyl-3-methylimidazoliumbis(trifluoromethylsulfonyl)imide saturated with silver trifluoromethanesulfonate $(0.18$ $\mathrm{g} / \mathrm{mL}$ ) to give a highly ethene selective porous liquid (PL2, Table 2). Notably, although its ethene/ethane selectivity (25.6 for $12.5 \mathrm{wt} . \%, 0.8$ bar and 21.0 for $25.0 \mathrm{wt} . \%$; 0.8 bar) was lower than that of the pure AgIL (33.13, 0.8 bar) due to the relatively lower ethene selectivity of zeolite $\mathrm{AgA}$ (15.48, 0.8 bar). However, its capacity was substantially greater $(0.61 \mathrm{mmol} / \mathrm{g}$ vs. $0.50 \mathrm{mmol} / \mathrm{g})$ due to zeolite additive, which could be advantageous in separation processes (SI 7, Table S6). PL-2 therefore illustrates that addition of an appropriate porous solid can increase the gas capacity of an ionic liquid even when it is saturated with a metal salt. PL-2 and PL-3 were stable for at least 2 days before sedimentation was observed visually and by $\mathrm{PXRD}^{7}$ (SI 8, Figure S23). The stability could potentially be improved further if required by reducing the $\mathrm{AgA}$ particle size or by surface modification for example.

The selectivity of PL-2 remains high at greater pressures ( 9.5 at 5 bar) suggesting gas separation potential by pressure swing. However, despite its promising selectivity and capacity PL-2 was unexpectedly difficult to regenerate, requiring ca. 2 hours at $150^{\circ} \mathrm{C}$ (SI 7, Figure S21). Also, unexpectedly, $\operatorname{Ag}(\mathrm{I})$ was observed to deposit from the IL onto the solid $\mathrm{AgA}$ over time which reduces the gas uptakes (Figure 2) of the porous liquid (SI 6, Table S4). These aspects clearly limit the applicability of this porous liquid.

Since conventional liquid solvents have not yet been reported to show high selectivity for ethane, we turned to the interesting possibility of making an ethane-selective porous liquid. $\mathrm{Cu}(\mathrm{Qc})_{2}(\mathrm{Qc}=$ quinoline-5-carboxylate $)$ is a recently-reported microporous MOF material that shows selective uptake of ethane over ethene ( 3.70 at 1 bar). ${ }^{26}$ It has a number of other attractive features including the low cost of its components and its stability to water vapour under ambient conditions.

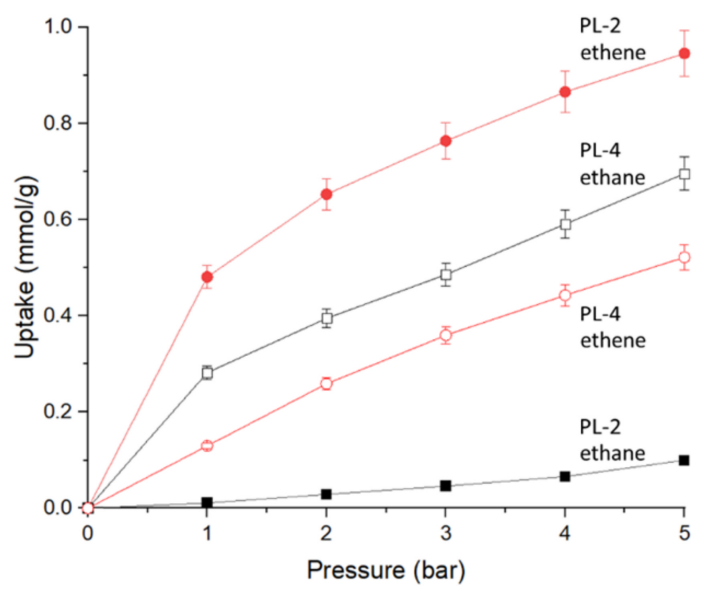

Figure 2. Barometric gas measurements of PL-2 (zeolite $\mathrm{AgA}$ in $\mathrm{AgIL})$ and PL-4 $\left(\mathrm{Cu}(\mathrm{Qc})_{2}\right.$ in sesame oil); black squares indicate ethane uptake and red circles indicate ethene uptake. Error bars for ethane are indistinguishable from the data points.

However, its reported solvothermal synthesis is low yielding $(6.9 \%){ }^{21} \mathrm{We}$ initially sought, therefore, to synthesise $\mathrm{Cu}(\mathrm{Qc})_{2}$ mechanochemically since this method can give quantitative yields for closely related MOFs such as $\mathrm{Cu}(\text { ina })_{2}$ (ina $=$ isonicotinic acid). ${ }^{27}$ After some optimisation, ball milling $\mathrm{Cu}(\mathrm{OH})_{2}$ with $\mathrm{HQc}$ in a steel jar at $25 \mathrm{~Hz}$ for 15 minutes in the presence of small amounts $(0.25 \mathrm{~mL})$ of DMF and $\mathrm{EtOH}$, gave quantitative conversion to $\mathrm{Cu}(\mathrm{Qc})_{2}$ (isolated yield $73.5 \%$ ) with no starting materials or by-products observed by PXRD (SI 5, Figure S2). $\mathrm{N}_{2-}$ Brunauer-Emmett-Teller $\left(\mathrm{N}_{2}\right.$-BET) surface areas of the mechanochemically prepared and conventionally prepared $\mathrm{Cu}(\mathrm{Qc})_{2}$ were similar at $340 \mathrm{~m}^{2} / \mathrm{g}$ and $437 \mathrm{~m}^{2} / \mathrm{g}$ respectively. Both compare favourably to the literature value (222 $\left.\mathrm{m}^{2} / \mathrm{g}\right){ }^{21}$ Since vibrational milling gives ready access to gram amounts of $\mathrm{Cu}(\mathrm{Qc})_{2}$ it is likely that larger scale twin screw extrusion techniques ${ }^{28}$ could provide give $\mathrm{kg}$ amounts if required. Furthermore, the particle size of the mechanochemically prepared $\mathrm{Cu}(\mathrm{Qc})_{2}(150 \mathrm{~nm})$ is smaller than the conventionally prepared $\mathrm{Cu}(\mathrm{Qc})_{2}(4 \mu \mathrm{m})$. Porous solids with smaller particle size should lead to better dispersion stability when formulating the porous liquid.

The mechanochemical product dispersed readily into sesame oil by simple magnetic stirring $(600 \mathrm{rpm})$ for 2 hours to give a purple suspension, PL-4 (Table 2) with high gas uptake compared to sesame oil alone (Figure 2) and increased selectivity for ethane over ethene at both 1 and 5 bar (2.17 and 1.33 respectively). Remarkably, despite the simple preparative method, it was stable to sedimentation for at least 14 days as determined by PXRD analysis and 
visual inspection (SI 8, Figure S22). Significantly, consistent with the physical rather than chemical binding of the ethane, it was also easily regenerated under mild conditions $\left(40^{\circ} \mathrm{C}, 1\right.$ hour) to regain, within error, similar gas uptake capacity (Figure 3), suggesting potential for cyclic separations.

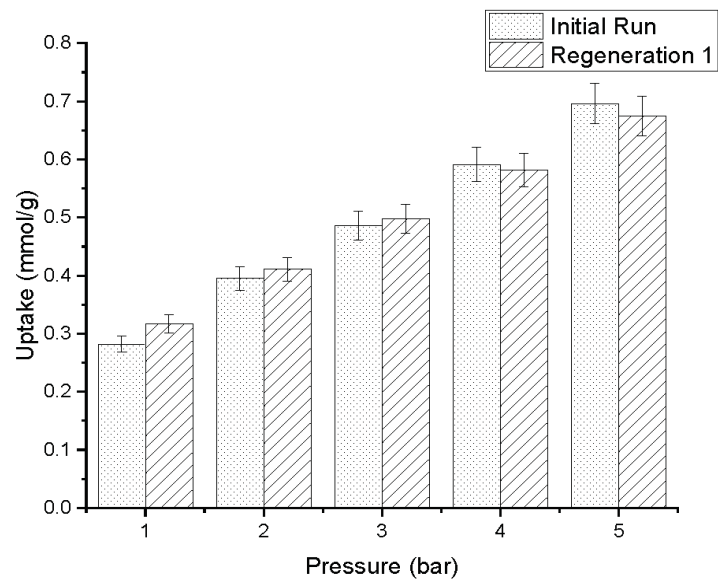

Figure 3. Ethane uptake of PL-4, $\mathrm{Cu}(\mathrm{Qc})_{2}$ in sesame oil. Regeneration conditions were $40^{\circ} \mathrm{C}$ for 1 hour.

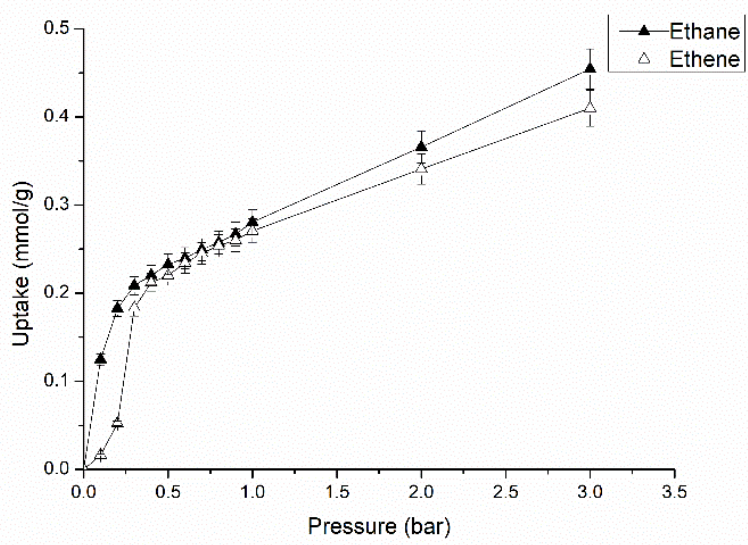

Figure 4. Barometric gas measurements of ZIF-7 in sesame oil. black squares indicate ethane uptake and red circles indicate ethene uptake. Error bars for ethane are indistinguishable from the data points.

A further porous liquid investigated was based on ZIF-7, $\mathrm{Zn}$ (benzimidazole) ${ }_{2}$, a solid which shows gating behaviour with regard to ethane and ethene uptake. Specifically, due to flexibility in the framework increasing gas pressure causes a structural change that allows gas to enter above a threshold pressure (<0.1 bar for ethane; 0.2-0.3 bar for ethene) ${ }^{23}$ There is thus a pressure window between $0.1-0.2$ bar where it shows high selectivity to ethane. Gated effects can be advantageous in gas uptake and release because large amounts of gas adsorb and desorb by small pressure change. 23,29
ZIF-7 was dispersed in sesame oil to form PL-5. Ethane and ethene uptakes were measured from 0-3 bar. As hoped, the gating behaviour of the MOF was preserved upon dispersion in the oil, and PL-5 showed high ethane selectivity of 7.5 at 0.1 bar (Figure 4 ). The ethane selectivity decreases markedly above ca. 0.25 bar suggesting that $0.1-0.2$ bar is the optimum pressure range to separate ethane/ethene at 298 K. Furthermore, PL-5 was easily regenerated with mild heating $\left(50^{\circ} \mathrm{C}\right)(\mathrm{SI} 7$, Figure S20) suggesting applicability in temperature swing absorption.

PL-5 demonstrates how relatively complex gas uptake behaviour (i.e., gating) that is well documented in framework solids can be readily imparted to the liquid state through dispersion in a size-excluded liquid. As such the uptake isotherms of PL-5 are very unusual, and possibly unique, for liquid phases.

\section{Conclusions}

In summary, in this study five PLs were formulated and evaluated for their potential in ethane/ethene separation. Some key observations are $i$. ethene capacity can be increased by adding a porous solid even when the liquid component is saturated with metal ions (PL-2), ii. PLs provide a way to make liquid phases with higher ethane selectivity than is possible for conventional solvents (PL-4 and PL-5), iii. regeneration is readily achieved for ethaneselective PLs that bind gases through physical rather than chemical interactions (PL-4 and PL-5), and $i v$. gated gas uptake behaviour of MOFs can be transferred to porous liquids (PL-5).

Regarding the relative merits of each porous liquid, PL-1 (HKUST-1 in sesame oil) has high uptake but low selectivity, limiting its applicability. PL-2 (zeolite AgA in AgIL) has high ethene selectivity, but is hard to regenerate and has low chemical stability. Conversely, ethaneselective PL-4 $\left(\mathrm{Cu}(\mathrm{Qc})_{2}\right.$ in sesame oil) and PL-5 (ZIF-7 in sesame oil) are easily regenerated and have high chemical stabilities. While PL-5 exhibits interesting gated behaviour, we note that the broader pressure range of ethane selectivity exhibited by PL-4, together with its ease of synthesis and high stability to sedimentation make this porous liquid of particular interest for ethane/ethene separation.

\section{ASSOCIATED CONTENT}

\section{Supporting Information}

The Supporting Information is available free of charge on the ACS Publications website.

Synthesis details, characterization, ethane/ethene uptakes results (PDF)

\section{AUTHOR INFORMATION}

\section{Corresponding Author}

*Email: S.James@qub.ac.uk (S.L. James.).

\section{Funding Sources}

InvestNI (PoC grant number 620) 
EPSRC (grant number R005540)

\section{Notes}

The authors declare no competing financial interest.

\section{ACKNOWLEDGMENT}

We acknowledge funding from InvestNI (PoC grant number 620) and EPSRC (grant number R005540).

\section{ABBREVIATIONS}

PLs, porous liquids; T3PLs, Type 3 porous liquids; AgIL, 1butyl-3-methylimidazolium bis(trifluoromethylsulfonyl)imide saturated with silver trifluoromethanesulfonate.

\section{REFERENCES}

(1) O'Reilly, N.; Giri, N.; James, S. L. Porous Liquids. Chem. Eur. J. 2007, 13, 3020-3025.

(2) Giri, N.; Del Pópolo, M. G.; Melaugh, G.; Greenaway, R. L.; R-Ratzke, K.; Koschine, T.; Pison, L.; Gomes, M. F. C.; Cooper, A. I.; James, S. L. Liquids with Permanent Porosity. Nature. 2015, 527, 216-220.

(3) Mastalerz, M. Liquefied Molecular Holes. Nature. 2015, 527, 174-175.

(4) Zhang, J.; Chai, S. H.; Qiao, Z. A.; Mahurin, S. M.; Chen, J.; Fang, Y.; Wan, S.; Nelson, K.; Zhang, P.; Dai, S. Porous Liquids: A Promising Class of Media for Gas Separation. Angew. Chem. Int. Ed. 2015, 54, 932-936.

(5) James, S. L. The Dam Bursts for Porous Liquids. Adv. mater. 2016, 28, 5712-5716.

(6) Li, P.; Schott, J. A.; Zhang, J.; Mahurin, S. M.; Sheng, Y.; Qiao, Z.A.; Hu, X.; Cui, G.; Yao, D.; Brown, S.; Zheng, Y.; Dai, S. Electrostatic-Assisted Liquefaction of Porous Carbons. Angew. Chem. Int. Ed. 2017, 56, 14958-14962.

(7) Cahir, J.; Tsang, M. Y.; Lai, B.; Hughes, D.; Ashraf-Alam, M.; Jacquemin, J.; Rooney, D.; James, S. L. Type 3 Porous Liquids Based on Non-ionic Liquid Phases - a Broad and Tailorable Platform of Selective, Fluid Gas Sorbents. Chem. Sci. 2020, 11, 2077-2084.

(8) Shan, W.; Fulvio, P. F.; Kong, L.; Schott, J. A.; Do-Thanh, CL.; Tian, T.; Hu, X.; Mahurin, S. M.; Xing, H.; Dai, S. New Class of Type III Porous Liquids: A Promising Platform for Rational Adjustment of Gas Sorption Behavior. Appl. Mater. Inter. Interfaces. 2018, 10, 32-36.

(9) Liu, S.; Liu, J.; Hou, X.; Tong, J.; Zhang, J.; Ye, B.; Liu, B. Porous Liquid: A Stable ZIF-8 Colloid in Ionic Liquid with Permanent Porosity. Langmuir. 2018, 34, 3654-3660.

(10) Gomes, M. C.; Pison, L.; Cervinka, C.; Padua, A. Porous Ionic Liquids or Liquid Metal-Organic Frameworks? Angew. Chem. Int. Ed. 2018, 57, 11909-11912.

(11) Liu, H,; Liu, B.; Lin, L-C.; Chen, G.; Wu, Y.; Wang, J.; Gao, X. Lv, Y.; Pan, Y.; Zhang, X.; Zhang, X.; Yang, L.; Sun, C.; Smit, B.; Wang, W. A Hybrid Absorption-Adsorption Method to Efficiently Capture Carbon. Nat. Commun. 2014, 5, 5147-5154.

(12) Pan, Y.; Li, H.; Zhang X-X.; Zhang, Z.; Tong, X-S.; Jia, CZ.; Liu, B.; Sun, C-Y.; Yang, L-Y.; Chen, G-J. Large-Scale Synthesis of ZIF-67 and Highly Efficient Carbon Capture Using a
ZIF-67/Glycol-2-methylimidazole Slurry. Chem. Eng. Sci. 2015, 137, 504-514.

(13) He, S.; Chen, L.; Cui, J.; Yuan, B.; Wang, H.; Wang, F.; Yu, Y.; Lee, Y.; Li, T. General Way to Construct Micro- and Mesoporous Metal-Organic Framework-Based Porous Liquids. J. Am. Chem. Soc. 2019, 141, 19708-19714.

(14) Knebel, A.; Bavykina, A.; Datta, S. J.; Sundermann, L.; Garzon-Tovar, L.; Lebedev, Y.; Durini, S.; Ahmad, R.; Kozlov, S. M.; Shterk, G.; Karunakaran, M.; Carja, I. D.; Simic, D.; Weilert, I.; Klüppel, M.; Giese, U.; Cavallo, L.; Rueping, M.; Eddaoudi, M.; Caro, J.; Gascon, J. Solution processable metal-organic frameworks for mixed matrix membranes using porous liquids. Nat. Mater. 2020, 19, 1346-1353.

(15) Azhin, M.; Kaghazchi, T.; Rahmani, M. A review on Olefin/Paraffin Separation Using Reversible Chemical Complexation Technology. J. Ind. Eng. Chem. 2008, 14, 622-638.

(16) Bux, H.; Chmelik, C.; Krishna, R.; Caro, J. Ethene/ethane Separation by the MOF Membrane ZIF-8: Molecular Correlation of Permeation, Adsorption, Diffusion. J. Membr. Sci. 2011, 369, 284-289.

(17) Bachman, J. E.; Smith, Z. P.; Li, T.; Xu, T.; Long, J. R. Enhanced Ethylene Separation and Plasticization Resistance in Polymer Membranes Incorporating Metal-Organic Framework Nanocrystals. Nat. Mater. 2016, 15, 845-849.

(18) Galan Sanchez, L. M.; Wytze Meindersma, G.; Hann, A. B. Potential of Silver-Based Room-Temperature Ionic Liquids for Ethylene/Ethane Separation. Ind. Eng. Chem. Res. 2009, 48, 10650-10656.

(19) Aguado, S.; Bergeret, G.; Daniel, C.; Farrusseng, D. Absolute Molecular Sieve Separation of Ethylene/Ethane Mixtures with Silver Zeolite A. J. Am. Chem. Soc. 2012, 134, 14635-14637.

(20) Wu, Y.; Sun, Y.; Xiao, J.; Wang, X.; Li, Z. Glycine-Modified HKUST-1 with Simultaneously Enhanced Moisture Stability and Improved Adsorption for Light Hydrocarbons Separation, ACS Sustainable Chem. Eng. 2019, 7,1557-156.

(21) Lin, R-B.; Wu, H.; Li, L.; Tang, X.; Li, Z.; Gao, J.; Cui, H.; Zhou, W.; Chen, B. Boosting Ethane/Ethylene Separation within Isoreticular Ultramicroporous Metal-Organic Frameworks. J. Am. Chem. Soc. 2018, 140, 12940-12946.

(22) Ploegmakers, J.; Japip, S.; Nijmeijer, K. Mixed Matrix Membranes Containing MOFs for Ethylene/Ethane Separation Part A: Membrane Preparation and Characterization. J. Membr. Sci. 2013, 428, 445-453.

(23) Gu “cu "yener, C.; Bergh, J.; Gascon, J.; Kapteijn, F. Ethane/Ethene Separation Turned on Its Head: Selective Ethane Adsorption on the Metal-Organic Framework ZIF-7 through a Gate-Opening Mechanism. J. Am. Chem. Soc. 2010, 132, 17704 17706.

(24) Stricker, M.; Oelkers, B.; Rosenau, C. P.; Sundermeyer, J. Copper(I) and Silver(I) Bis(trifluoromethanesulfonyl)imide and Their Interaction with an Arene, Diverse Olefins, and an NTf2-Based Ionic Liquid. Chem. Eur. J. 2013, 19, 1042-1057.

(25) He, Y.; Krishna R.; Chen, B. Metal-Organic Frameworks with Potential for Energy-Efficient Adsorptive Separation of Light Hydrocarbons. Energy Environ. Sci. 2012, 5, 9107-9120.

(26) Tang, Y.; Wang, S.; Zhou, X.; Wu, Y.; Xian, S.; Li, Z. Room Temperature Synthesis of $\mathrm{Cu}(\mathrm{Qc})_{2}$ and Its Application for Ethane Capture from Light Hydrocarbons. Chem. Eng. Sci. 2020, 213, 115355-115363. 
(27) Pichon, A.; Lazuen-Garay, A.; James, S. L.; Solvent-free Synthesis of a Microporous Metal-Organic Framework. CrystEngComm. 2006, 8, 211-214.

(28) Crawford, D.; Casaban, J.; Haydon, R.; Giri, N.; McNally, T.; James, S. L. Synthesis by Extrusion: Continuous, Large-Scale Preparation of MOFs Using Little or No Solvent. Chem. Sci. 2015, 6, 1645-1649.

(29) Chen, D-L.; Wang, N.; Xu, C.; Tu, G.; Zhu, W.; Krishna, R. A Combined Theoretical and Experimental Analysis on Transient Breakthroughs of $\mathrm{C}_{2} \mathrm{H}_{6} / \mathrm{C}_{2} \mathrm{H}_{4}$ in Fixed Beds Packed with ZIF-7. Micropor. Mesopor. Mater. 2015, 208, 55-65. 